\title{
An experimental approach to study the function of mitochondria in cardiomyopathy
}

\author{
Youn Wook Chung ${ }^{1}$ E Seok-Min Kang ${ }^{1,2,3, *}$ \\ ${ }^{1}$ Yonsei Cardiovascular Research Institute, Yonsei University College of Medicine, Seoul 03722, ${ }^{2}$ Cardiology Division, Severance \\ Cardiovascular Hospital, Seoul 03722, ${ }^{3}$ Severance Integrative Research Institute for Cerebral and Cardiovascular Diseases (SIRIC), Yonsei \\ University Health System, Seoul 03722, Korea
}

\begin{abstract}
Cardiomyopathy is an inherited or acquired disease of the myocardium, which can result in severe ventricular dysfunction. Mitochondrial dysfunction is involved in the pathological process of cardiomyopathy. Many dysfunctions in cardiac mitochondria are consequences of mutations in nuclear or mitochondrial DNA followed by alterations in transcriptional regulation, mitochondrial protein function, and mitochondrial dynamics and energetics, presenting with associated multisystem mitochondrial disorders. To ensure correct diagnosis and optimal management of mitochondrial dysfunction in cardiomyopathy caused by multiple pathogenesis, multidisciplinary approaches are required, and to integrate between clinical and basic sciences, ideal translational models are needed. In this review, we will focus on experimental models to provide insights into basic mitochondrial physiology and detailed underlying mechanisms of cardiomyopathy and current mitochondria-targeted therapies for cardiomyopathy. [BMB Reports 2015; 48(10): 541-548]
\end{abstract}

\section{INTRODUCTION}

Mitochondrial dysfunction plays a critical role in the underlying pathological process of ischemic heart disease (IHD) and cardiomyopathy (CM) (1). As a leading cause of death worldwide (2), IHD (also known as coronary artery disease) is primarily caused by acute myocardial infarction (AMI). A precursor to heart failure, CM is acutely caused by myocardial ischemia and chronically by hypertension or diabetes mellitus. Mitochondrial damage occurs primarily during the reperfusion phase of ischemia/reperfusion (I/R) $(3,4)$. In the post-I/R heart, mitochondrial dysfunctions are due to inhibition of electron transport chain (ETC) function and oxygen $\left(\mathrm{O}_{2}\right)$ consumption,

${ }^{*}$ Corresponding author. Tel: +82-2-2228-1042; Fax: +82-2-3638676; E-mail: smkang@yuhs.ac

http://dx.doi.org/10.5483/BMBRep.2015.48.10.153

Received 20 July 2015

Keywords: Cardiomyopathy, Heart, Mitochondria mitochondrial calcium $\left(\mathrm{Ca}^{2+}\right)$ overload, reactive oxygen species (ROS) generation, mitochondrial permeability transition (MPT) pore opening, loss of mitochondrial membrane potential $(\Delta \Psi \mathrm{m})$, and increased mitochondrial necrosis and apoptosis (5-7). Alteration of mitochondrial energy metabolism also plays a substantial role in IHD and CM (8). Not surprisingly, mitochondria are a potential therapeutic target for IHD and CM.

\section{CARDIOMYOPATHY}

The heart is composed mostly of the cardiac muscle, or myocardium. Severe or long-standing problems with the cardiac muscle can lead to heart failure. Inflammation of the heart is called myocarditis, whereas non-inflammatory cardiac muscle disease is known as $\mathrm{CM}$, in which the myocardium becomes damaged, weakened, or stretched by various causes. Clinically, $\mathrm{CM}$ is divided into ischemic $\mathrm{CM}$ and non-ischemic $\mathrm{CM}$, and in turn non-ischemic CM includes three types: dilated (DCM), hypertrophic $(\mathrm{HCM})$, and restrictive $(\mathrm{RCM})(9,10)$. DCM is characterized by enlargement of the heart and dilated ventricle walls, which associated with reduced left ventricle function or systolic function. In contrast, HCM is characterized by a thickened wall of the left ventricle and/or by a thickened septum that separates the left ventricle and the right ventricle. In the condition of RCM, the walls of the ventricles become rigid, which reduces cardiac output due to diastolic dysfunction. Over the past few decades, another type of CM called mitochondrial $\mathrm{CM}$ has emerged and has been extensively studied. The clinical and pathological phenotype of mitochondrial $\mathrm{CM}$, which is primarily found in DCM, HCM, arrhythmias and heart failure, results from abnormalities in the cardiac mitochondrial oxidative phosphorylation (OXPHOS) system, due to genetic defects (11).

\section{MITOCHONDRIAL DEFECTS IN EXPERIMENTAL MODELS OF CARDIOMYOPATHY}

Mitochondrial dysfunction plays a critical role in the pathogenesis of $\mathrm{CM}(12,13)$. Among various animal models that have been established to study the process and mechanisms

ISSN: 1976-670X (electronic edition)

Copyright (c) 2015 by the The Korean Society for Biochemistry and Molecular Biology

(c) This is an open-access article distributed under the terms of the Creative Commons Attribution Non-Commercial License (http://creativecommons.org/licenses/by-nc/4.0) which permits unrestricted non-commercial use, distribution, and reproduction in any medium, provided the original work is properly cited. 
involved in cardiac disease (14-16), many exhibit CM phenotypes associated with mitochondrial defects (Table 1).

\section{Transcriptional regulation}

As with nuclear DNA (nDNA), mitochondrial DNA (mtDNA) is subject to epigenetic modifications related to energetic capacity and disease status. When calories are limited, gene expression is suppressed due to decreased phosphorylation and acetylation of chromatin (17). Sirtuins, or the Silent Information Regulator 2 (SIR2) protein family includes 7 (Sirt1-7) nicotinamide adenine

Table 1. Experimental models for cardiomyopathy with mitochondrial dysfunction

\begin{tabular}{|c|c|c|c|c|c|}
\hline & Modification & Species & Phenotype & Mitochondrial abnormalities & Ref. \\
\hline \multirow{4}{*}{$\begin{array}{l}\text { Transcriptional } \\
\text { regulation }\end{array}$} & $\mathrm{CAP}^{\mathrm{R}} \mathrm{mtDNA}$ germ-line transmission & Mouse & DCM & Enlarged mitochondria & (22) \\
\hline & Tfam cKO & Mouse & DCM & Respiration $\downarrow$ & (52) \\
\hline & Sirt7 KO & Mouse & $\mathrm{CM}$ & Acetylation of GABP $\beta 1 \uparrow$ & (19) \\
\hline & Ncoa6 cKO or DN1 TG & Mouse & DCM & Complex II $\downarrow$ & (20) \\
\hline \multirow{8}{*}{$\begin{array}{l}\text { Mitochondrial } \\
\text { protein } \\
\text { function }\end{array}$} & $\begin{array}{l}\text { Scgd deficient } \\
\text { (BIO 14.6) }\end{array}$ & Hamster & Congenital CM & $\begin{array}{l}\text { St } 3 \text { in IFM } \downarrow \\
\mathrm{Ca}^{2+} \text { overload }\end{array}$ & $\begin{array}{l}(31) \\
(95)\end{array}$ \\
\hline & Sod2 KO & Mouse & Neonatal DCM & Complex II $\downarrow$ & $(73,96)$ \\
\hline & Ant1 KO & Mouse & $\mathrm{HCM}$ & Respiration $\downarrow$, ROS $\uparrow$ & (57) \\
\hline & Nix/Bnip3 DKO & Mouse & $\mathrm{CM}$ & $\begin{array}{l}\text { Accumulation of } \\
\text { abnormal mitochondria }\end{array}$ & (37) \\
\hline & CryAB ${ }^{R 120 G}$ mutation & Mouse & $\begin{array}{l}\text { Desmin-related } \\
\text { CM }\end{array}$ & $\begin{array}{l}\text { Complex I } \downarrow \\
\text { MPT pore opening } \uparrow \\
\Delta \Psi \mathrm{m} \downarrow\end{array}$ & (62) \\
\hline & Dystrophin-deficient $(m d x)$ & Mouse & $\mathrm{CM}$ & $\begin{array}{l}\text { Substrate shift } \\
\mathrm{O}_{2} \text { consumption } \uparrow\end{array}$ & (66) \\
\hline & LTCC $\beta 2$ a subunit cTG & Mouse & $\mathrm{CM}$ & $\mathrm{Ca}^{2+}$ overload & (67) \\
\hline & MutUNG1 TG & Mouse & $\mathrm{HCM}$ & $\begin{array}{l}\text { mtDNA stability } \downarrow \\
\text { Respiration } \downarrow\end{array}$ & (21) \\
\hline \multirow{5}{*}{$\begin{array}{l}\text { Mitochondrial } \\
\text { dynamics }\end{array}$} & $D n m 1 l^{P y /+}$ & Mouse & $\mathrm{CM}$ & ATP $\downarrow$ & (49) \\
\hline & Mfn1/2 DKO & Mouse & $\mathrm{DCM}$ & $\begin{array}{l}\text { Mitochondrial fragmentation } \uparrow \\
\text { Respiration } \downarrow\end{array}$ & $(39,42,43)$ \\
\hline & $O p a 1^{+/-}$ & Mouse & $\mathrm{CM}$ & $\begin{array}{l}\text { mtDNA stability } \downarrow \\
\text { Mitochondrial fragmentation } \uparrow\end{array}$ & (44) \\
\hline & Mfn2 KO & Mouse & DCM & $\begin{array}{l}\mathrm{O}_{2} \text { consumption } \downarrow \\
\text { ROS } \uparrow\end{array}$ & $\begin{array}{l}(40) \\
(41)\end{array}$ \\
\hline & Drp1 cKO & Mouse & $\mathrm{DCM}$ & $\begin{array}{l}\text { Mitophagy } \uparrow \\
\text { MPT pore opening } \uparrow\end{array}$ & (39) \\
\hline \multirow[t]{4}{*}{ Induced models } & DOX-induced model & $\begin{array}{l}\text { Rabbit } \\
\text { Mouse } \\
\text { Rat }\end{array}$ & $\mathrm{CM}$ & $\operatorname{ROS} \uparrow$ & $\begin{array}{l}(79) \\
(78) \\
(80)\end{array}$ \\
\hline & Pacing-induced model & Dog & DCM & $\begin{array}{l}\text { Complex I } \downarrow \\
\operatorname{ROS} \uparrow\end{array}$ & (72) \\
\hline & Fz-induced model & $\begin{array}{l}\text { Turkey } \\
\text { Rat }\end{array}$ & DCM & $\begin{array}{l}\text { Mitochondrial swelling } \uparrow \\
\text { Complex II, IV } \downarrow \\
\Delta \Psi \mathrm{m} \downarrow\end{array}$ & $\begin{array}{l}(68) \\
(69)\end{array}$ \\
\hline & Autoantibodies $\left(\mathrm{M}_{2}-\mathrm{AA}\right)$ & Rat & DCM-like & Mitochondrial swelling $\uparrow$ & (26) \\
\hline
\end{tabular}

CAP : chloramphenicol-resistant, mtDNA: mitochondrial DNA, Tfam: mitochondrial transcription factor A (mtTFA), KO: knock out, cKO: conditional KO, Sirt7: sirtuin 7, GABP $\beta 1$ : GA binding protein $\beta 1$, Ncoa6: nuclear receptor coactivator 6, DN1: dominant-negative mutant containing an $\mathrm{N}$-terminal LXXLL-1 motif of NCOA6, TG: transgenic, Scgd: $\delta$-sarcoglycan, BIO 14.6: Syrian cardiomyopathic hamster, St3: state 3 (ADP-stimulated) respiration, IFM: interfibrillar mitochondria, Sod2: superoxide dismutase 2 (mitochondrial, manganese superoxide dismutase), Ant1: adenine nucleotide translocator, ROS: reactive oxygen species, DKO: double KO, CryAB: $\alpha$-B-crystallin, mdx: X chromosome-linked muscular dystrophy, LTCC: L-type $\mathrm{Ca}^{2+}$ channel, mut: mutant, UNG1: uracil-DNA glycosylase 1, Dnm1l: dynamin-1-like, Py: Python (a mouse mutant), Mfn2: mitofusin 2, Opa 1: optic atrophy 1, Drp1: dynamin-related protein 1, MPT pore: mitochondrial permeability transition pore, DOX: doxorubicin, Fz: furazolidone, $\mathrm{M}_{2}-\mathrm{AA}: \mathrm{M}_{2}$ muscarinic receptor, $\Delta \Psi \mathrm{m}$ : mitochondrial membrane potential. 
dinucleotide $\left(\mathrm{NAD}^{+}\right)$-dependent histone deacetylases (HDACs). Since sirtuins require $\mathrm{NAD}^{+}$for their deacetylase activity, they are tightly linked to cellular energy status, such as exercise and caloric restriction. Among the 7 isoforms, mitochondrial Sirt3, and nuclear Sirt6 and Sirt7 are implicated in left ventricular hypertrophy, CM, and lipid metabolism (18). In Sirt7-deficient mice, SIRT7-mediated deacetylation of GA binding protein $\beta 1$ (GABP 31 ), a master transcription factor of nDNA-encoded mitochondrial genes, is inhibited. The reduction in deacetylation level of GABP $\beta 1$ and the associated transcriptional activity results in multisystemic mitochondrial dysfunction, including CM (19). Recently, we found that either cardiomyocyte-specific ablation of nuclear hormone receptor coactivator (NCOA6) or overexpression of a dominant-negative mutant form of NCOA6 (DN1) leads to development of severe DCM with impaired mitochondrial function (20). Ncoa6 deficiency reduces activity of peroxisome proliferator-activated receptor $\delta$ (PPAR $\delta$ ), transcription levels of its target genes, the number of mitochondria in cardiomyocytes, and complex II activity (20). However, it is still unknown if morphologic and functional abnormalities of cardiac mitochondria in Ncoa6 deletion mice are causes or results of DCM. Cardiomyocyte-specific expression of a mutant uracil-DNA glycosylase 1 (mutUNG1) leads to development of $\mathrm{HCM}$, demonstrating that mtDNA toxicity-induced mitochondrial dysfunction leads to heart failure. In this transgenic mouse heart, increased mitochondrial mass, reduced mtDNA transcription, and suppressed mitochondrial respiration with impaired mitochondrial fission and fusion dynamics were observed (21).

\section{Morphologic changes of mitochondria}

The introduction of the mtDNA $16 \mathrm{~S}$ ribosomal RNA (rRNA) chloramphenicol (CAP) resistance mutation into the mouse female germ line causes $\mathrm{CM}$ in chimeric mice. In CAP-resistant $\left(C A P^{R}\right)$ mouse skeletal muscle and heart, abnormally enlarged mitochondria were observed (22). Autoimmunity has been considered as one of major causes for idiopathic DCM (23), and high titers of autoantibodies $\left(\mathrm{M}_{2}-\mathrm{AA}\right)$ against the second extracellular loop of the $\mathrm{M}_{2}$ muscarinic receptor $\left(\mathrm{M}_{2} \mathrm{AChR}-\mathrm{el} 2\right)$ has been found in serum of patients with idiopathic DCM (24). Animal models have been established by immunizing rats (25, 26) or mice (27) with synthetic $M_{2} A C h R-e l 2$ peptide to induce DCM-like morphological changes in the animals' heart. $\mathrm{M}_{2} \mathrm{AChR}$ el2-immunized rat heart showed decreased systolic and diastolic function with swollen and damaged mitochondria (26).

Two functionally distinct populations exist in cardiac mitochondria, interfibrillar mitochondria (IFM) and subsarcolemmal mitochondria (SSM). IFM is located between the myofibrils, whereas SSM is located beneath the plasma membrane. (28). Although the coupling of respiration is similar in both populations of mitochondria, the rate of substrate oxidation is greater in IFM than in $\operatorname{SSM}(29,30)$. Cardiac muscle cells in cardiomyopathic hamsters showed depressed oxidation rates in IFM, but not in SSM (31).
Dysfunction of mitochondrial dynamics and quality control Binding of agonist to $G$ protein-coupled receptor (GPCR) family triggers the dissociation of $\mathrm{Gq}$ protein into $\mathrm{G} \alpha q$ and $C \beta \gamma$ subunits. GTP-bound Gaq (active form) activates phospholipase $\mathrm{C}$ (PLC) and ultimately protein kinase C (PKC). As activation of MAP kinase by Gaq has been implicated in stimulating cardiac growth, transgenically overexpressed Gaq in mouse hearts causes myocardial hypertrophy with systolic dysfunction and DCM with cardiac contractile failure at high-expression levels (32). Combined with a pressure overload model by surgical transverse aortic constriction (TAC) (33), Gaq-mediated myocardial hypertrophy model has been used by the same research group to study roles of pro-apoptotic $\mathrm{Bcl}-2$ family protein Nix (also known as Bnip3L) and Bnip3 in cardiac hypertrophy and apoptotic CM (34-36). Proapoptotic Nix is induced in Gq-dependent and pressure overload hypertrophy, and cardiac-specific expression of Nix triggers apoptotic CM (34). Moreover, BNip3/Nix DKO induces the accumulation of abnormal mitochondria and causes $\mathrm{CM}$ due to mitophagic dysfunction (37).

Mitochondrial dynamics, mitochondrial fission and fusion, are involved in the mechanisms of a variety of human diseases including cancer, neurodegenerative diseases, and cardiovascular diseases (38). Dorn and his associates have intensively studied the connection between mitochondrial dynamics and CM (39-44). Using genetic ablations of the pro-fission factor dynamin-related protein 1 (Drp1) and the pro-fusion factors mitofusins (Mfn1, Mfn2, and Mfn1/2) and optic atrophy 1 (Opa1), they demonstrated that mitochondrial fission and fusion dynamism plays an important role in pathophysiology of $\mathrm{CM}$ and heart failure (45). Mitophagy, the autophagy of mitochondria, is a selective clearance process of damaged or aged mitochondria $(46,47)$. Regulation of mitophagy requires two Parkinson's disease factors, the mitochondrial kinase PINK1 (PTEN-induced putative kinase protein 1) and the cytosolic ubiquitin ligase Parkin (48). Mfn2-deficient mouse cardiomyocytes exhibited accumulation of morphologically and functionally abnormal mitochondria due to suppressed mitophagy and subsequent reduction of oxygen $\left(\mathrm{O}_{2}\right)$ consumption, suggesting that the mitochondrial respiratory impairment contributes to the development of DCM (40). Interrupting mitochondrial fusion by combined Mfn1/Mfn2 ablation in adult hearts increased mitochondrial fragmentation and induced mitochondrial respiratory dysfunction, causing lethal DCM $(39,42,43)$. Since the homozygous mutation is embryonic lethal, heterozygous $\mathrm{Opa}^{+-}$ mice were generated and examined. Abnormal cardiac function with reduced mtDNA stability and fragmented mitochondria was observed in aged Opa ${ }^{+1-}$ mouse heart, which develops late-onset CM (44). In contrast, cardiomyocyte-specific Drp1 knock out (KO) mice showing increased cardiomyocyte mitophagy and mitochondrial permeability transition (MPT) pore opening, led to cardiomyocyte necrosis and DCM (39). A mutation in another mitochondrial fission gene Dnm1l $\left(D n m 1 l^{P y / t}\right)$ also led to CM. ATP depletion observed in 
$D n m 1 l^{P y /+}$ mouse heart possibly contributes to CM (49). These studies suggest that the cardiac mitochondrial quality control process is critical in pathophysiology of CM.

\section{Impaired mitochondrial metabolism}

Transcription of mtDNA is controlled by nuclear gene-encoded regulatory proteins such as mitochondrial transcription factor $\mathrm{A}$ (Tfam, also known as mtTFA) $(50,51)$. Mutant animals, whose Tfam gene is disrupted in heart and muscle, developed DCM similar to Kearns-Sayre syndrome due to cardiac-specific inactivation of mtDNA gene expression (52) and cardiac respiratory chain dysfunction (53). The main function of mitochondria in the cardiac muscle is ATP synthesis via the OXPHOS system. Reducing equivalents, such as the reduced form of nicotinamide adenine dinucleotide (NADH) and flavin adenine dinucleotide $\left(\mathrm{FADH}_{2}\right)$ generated by the tricarboxylic acid (TCA) cycle following substrate oxidation (fatty acids or glucose), are used by the respiratory chain to produce an electrochemical gradient across the mitochondrial membrane [mitochondrial membrane potential $(\Delta \Psi \mathrm{m})]$ that drives ATP synthesis. In the adult myocardium, although both fatty acids and glucose are utilized, fatty acids are preferentially oxidized, supplying approximately $70 \%$ of total ATP $(54,97)$. In the failing heart, oxidation of carbohydrate substrates (glucose and lactate) is impaired and fatty acid oxidation (FAO) is enhanced (55). Heart failure patients may benefit from increasing oxidation of pyruvate which derives glucose and lactate, by pharmacologically activating pyruvate dehydrogenase (PDH) (56) (see section Mitochondria as a Therapeutic Target for Cardiomyopathy). Conditional KO mice of adenine nucleotide translocator (Ant1) revealed a dramatic proliferation of mitochondria and cardiac hypertrophy. As Ant1 KO also has the metabolic acidosis phenotype and its isolated mitochondria exhibited a severe defect in coupled respiration, it will be a good animal model to study all the biochemical, histological, metabolic and physiological characteristics of mitochondrial myopathy and CM (57). Desmin-related CM is caused by mutations in desmin, $\alpha$-B-crystallin (CryAB), and other genes $(58,59)$. In particular an R120G missense mutation in CryAB results in desmin-related $C M(60)$. Although desmin-related CM caused by mutations in desmin is not associated with mitochondria (61), a mouse model of desmin-related $C M$ caused by $C_{r y A B}{ }^{R 120}$ s sowed that reduced complex I activity with alterations in the MPT pore and mitochondrial membrane potential $(\Delta \Psi \mathrm{m})$ eventually resulted in cardiac cell death, CM, and heart failure (62). Since deficiencies in the cytoskeletal protein dystrophin have been implicated in the pathogenesis of both genetic and acquired forms of $\mathrm{CM}$ (63-65), the dystrophin-deficient $m d x$ mouse is considered a good experimental model for $\mathrm{CM}$. In the $m d x$ mouse heart, a marked shift in substrate from fatty acids to carbohydrates associated with enhanced oxygen consumption was observed (66). Overexpression of the LTCC $\beta 2$ a subunit enhanced $\mathrm{Ca}^{2+}$ influx-induced cellular necrosis and induced $\mathrm{CM}$, supporting the concept that necrosis associated with $\mathrm{Ca}^{2+}$ overload can also contribute to loss of cardiomyocytes in heart failure (67). Furazolidone (Fz), a nitrofuran antibacterial, used to establish a turkey model of DCM, with similarities to DCM in human (68), was also used to establish a rat model of DCM (69). The Fz-induced rat model heart showed significant myocardial degeneration and mitochondrial swelling with decreases in mitochondrial membrane potential $(\Delta \Psi \mathrm{m})$ and activities of complex II and IV (69).

Together with small animal models, large animal models are needed to translate discoveries from the basic sciences into clinical applications. The pacing-induced DCM model is obtained by continuous cardiac pacing at a higher frequency than the spontaneous heart rate in dogs, pigs, sheep and monkeys $(70,71)$. In a pacing-induced canine model of DCM, decreases in the enzymatic activity of complex I were observed (72).

\section{Increased oxidative stress}

Superoxide dismutase 2 (SOD2, also known as mitochondrial MnSOD) mutant mice developed a neonatal $\mathrm{CM}$, indicating that mitochondrial ROS can cause accumulation of oxidative DNA damage (73). As described in the section Dysfunction of Mitochondrial dynamics and quality control, due to impaired Parkin-mediated mitophagy, Mfn2 KO hearts exhibit accumulation of damaged mitochondria, which produces ROS. Cardiomyocyte-specific expression of mitochondrial-targeted catalase reversed ROS-mediated dysfunction of mitochondrial quality control mechanisms in Mfn2 KO hearts (41). Mutation of the Ant1 gene also increases mitochondrial ROS production (57). The most effective anti-cancer drug, doxorubicin (DOX), has been reported to have cardiotoxicity $(74,75)$ and thus DOX-induced CM has been considered a good model for studying congestive heart failure induced by anthracycline analogues (76, 77). Various DOX-induced CM animal models have been developed in mouse (78), rabbit (79), and rat (80). The increased superoxide production in pacing-induced canine model of DCM and heart failure suggested that complex I is a potential source of mitochondrial production of ROS in failing hearts (72). All these reports provide important insights into the role of mitochondrial ROS in the pathophysiology of CM.

\section{MITOCHONDRIA AS A THERAPEUTIC TARGET FOR CARDIOMYOPATHY}

The development of experimental models of mitochondrial heart diseases also provides the opportunity to investigate the efficacy of new mitochondria-targeting drugs and their underlying mechanisms of action. Many studies have targeted bioenergetic dysfunction of mitochondria by adding cofactors, such as coenzyme $\mathrm{Q}$ or L-carnitine to therapies for treatment of heart failure associated with CM $(81,82)$. Coenzyme Q10 (also known as ubiquinone) functions as an antioxidant and its deficiency is associated with CM (83). The coenzyme Q analog idebenone corrects cardiac diastolic dysfunction and im- 
proves exercise performance in the $m d x$ mouse model of Duchenne muscular dystrophy (DMD) (84). Although initial trials have shown some benefits in preventing progression of $\mathrm{HCM}$, recent controlled trials reported that idebenone neither decreased left ventricular hypertrophy nor improved cardiac function in patients with Friedreich's ataxia (FRDA) $(81,85)$. Long-term administration of L-carnitine for the treatment of $\mathrm{HF}$ caused by DCM showed improved survival (86). The carnitine palmitoyltransferase 1 (CPT-I) inhibitor, perhexilin, corrected energy deficiency caused by diastolic dysfunction and improved exercise capacity in HCM patients, suggesting its function as a metabolic modulator (shifting FAO to glucose oxidation) (87). Another CPT-I inhibitor, oxfenicine showed similar effects in dog heart, in which CPT-I inhibition prevents ventricular remodeling (88). Dichloroacetate (DCA) is another potential therapy for $\mathrm{CM}$, by stimulating pyruvate dehydrogenase is stimulated to drive pyruvate to mitochondrial OXPHOS, increasing acetyl-CoA and NADH levels. However, treatment of non-ischemic and ischemic DCM patients with DCA showed inconsistent effects on left ventricular mechanical efficiency and myocardial $\mathrm{O}_{2}$ consumption $(89,90)$. L-arginine has also been proposed as a treatment for $\mathrm{CM}$. In patients with mitochondrial CM, L-arginine enhanced aerobic metabolism and myocardial efficiency, independent of its vasodilation effect (91). Because the primary target of DOX-induced CM is the mitochondria, in which DOX triggers the generation of ROS and lipid peroxidation $(76,77)$, numerous studies have tested iron-chelating agents [e.g., dexrazoxane (92)], antioxidants [e.g., MnTBAP and ebselen (93)], and the phosphodiesterase 5 inhibitor sildenafil (94) to prevent the mitochondrial dysfunctions in DOX-induced CM.

\section{CONCLUDING REMARKS}

Mitochondrial dysfunction is substantially involved in arrhythmogenic cardiac diseases, including inherited and acquired $\mathrm{CM}$. Alterations in mitochondrial morphology, impaired energy production (i.e. ATP synthesis) and enhanced pathologic function (i.e. ROS generation, $\mathrm{Ca}^{2+}$ overload and apoptosis) cause cardiomyocyte injury and/or cell death due to malfunction of cellular mechanisms involved in maintaining intracellular $\mathrm{Ca}^{2+}$ homeostasis and normal mechanical and electrical functions of heart.

Although interpretations must be made with appropriate caution, i.e. "a man will never be a mouse", studies of mitochondrial function in cardiac disease using animal models will undoubtedly continue to provide new insights into the mechanisms of cardiac mitochondrial damage and a better understanding of the mitochondrial-mediated injury pathways involved in $\mathrm{CM}$ and heart failure. Current pharmacologic strategies have not yet been proven effective, and large randomized controlled trials are needed to establish a link between mitochondria and CM. Cross-disciplinary analysis will hopefully provide unique insights into mitochondrial disorders and optimum translational models with which to challenge our perspectives on human $\mathrm{CM}$ and heart failure while also suggesting new therapeutic strategies.

\section{ACKNOWLEDGEMENTS}

This work was supported by the Basic Science Research Program through the National Research Foundation of Korea (NRF) funded by the Ministry of Education (NRF-2014R1A2A1A11052412).

\section{REFERENCES}

1. Walters AM, Porter GA Jr. and Brookes PS (2012) Mitochondria as a drug target in ischemic heart disease and cardiomyopathy. Circ Res 111, 1222-1236

2. Roger VL, Go AS, Lloyd-Jones DM et al (2012) Heart disease and stroke statistics-2012 update: a report from the American Heart Association. Circulation 125, e2-e220

3. Ambrosio G, Zweier JL, Duilio C et al (1993) Evidence that mitochondrial respiration is a source of potentially toxic oxygen free radicals in intact rabbit hearts subjected to ischemia and reflow. J Biol Chem 268, 18532-18541

4. Lucas DT and Szweda LI (1998) Cardiac reperfusion injury: aging, lipid peroxidation, and mitochondrial dysfunction. Proc Natl Acad Sci U S A 95, 510-514

5. Murphy E and Steenbergen C (2008) Mechanisms underlying acute protection from cardiac ischemia-reperfusion injury. Physiol Rev 88, 581-609

6. Brenner C and Moulin M (2012) Physiological roles of the permeability transition pore. Circ Res 111, 1237-1247

7. Kwong JQ and Molkentin JD (2015) Physiological and pathological roles of the mitochondrial permeability transition pore in the heart. Cell Metab 21, 206-214

8. Huss JM and Kelly DP (2005) Mitochondrial energy metabolism in heart failure: a question of balance. J Clin Invest 115, 547-555

9. Towbin JA and Bowles NE (2002) The failing heart. Nature 415, 227-233

10. Cecchi F, Tomberli B and Olivotto I (2012) Clinical and molecular classification of cardiomyopathies. Glob Cardiol Sci Pract 2012, 4

11. Ozawa T (1994) Mitochondrial cardiomyopathy. Herz 19, 105-118, 125

12. Stanley WC and Hoppel CL (2000) Mitochondrial dysfunction in heart failure: potential for therapeutic interventions? Cardiovasc Res 45, 805-806

13. Lesnefsky EJ, Moghaddas S, Tandler B, Kerner J and Hoppel CL (2001) Mitochondrial dysfunction in cardiac disease: ischemia-reperfusion, aging, and heart failure. J Mol Cell Cardiol 33, 1065-1089

14. Ikeda Y and Ross J Jr. (2000) Models of dilated cardiomyopathy in the mouse and the hamster. Curr Opin Cardiol 15, 197-201

15. Benjamin IJ and Schneider MD (2005) Learning from failure: congestive heart failure in the postgenomic age. J Clin Invest 115, 495-499

16. Recchia FA and Lionetti V (2007) Animal models of dilated cardiomyopathy for translational research. Vet Res 
Commun 31 Suppl 1, 35-41

17. Wallace DC and Fan W (2010) Energetics, epigenetics, mitochondrial genetics. Mitochondrion 10, 12-31

18. Winnik S, Auwerx J, Sinclair DA and Matter CM (2015) Protective effects of sirtuins in cardiovascular diseases: from bench to bedside. Eur Heart J [Epub ahead of print]

19. Ryu D, Jo YS, Lo Sasso G et al (2014) A SIRT7-dependent acetylation switch of GABPbeta1 controls mitochondrial function. Cell Metab 20, 856-869

20. Roh Jl, Cheong C, Sung YH et al (2014) Perturbation of NCOA6 leads to dilated cardiomyopathy. Cell Rep 8, 991-998

21. Lauritzen KH, Kleppa L, Aronsen JM et al (2015) Impaired dynamics and function of mitochondria caused by mtDNA toxicity leads to heart failure. Am J Physiol Heart Circ Physiol 309, H434-449

22. Sligh JE, Levy SE, Waymire KG et al (2000) Maternal germ-line transmission of mutant mtDNAs from embryonic stem cell-derived chimeric mice. Proc Natl Acad Sci U S A 97, 14461-14466

23. Baba A, Yoshikawa T, Fukuda Y et al (2004) Autoantibodies against M2-muscarinic acetylcholine receptors: new upstream targets in atrial fibrillation in patients with dilated cardiomyopathy. Eur Heart J 25, 1108-1115

24. Fu LX, Magnusson Y, Bergh CH et al (1993) Localization of a functional autoimmune epitope on the muscarinic acetylcholine receptor- 2 in patients with idiopathic dilated cardiomyopathy. J Clin Invest 91, 1964-1968

25. Fu ML, Schulze W, Wallukat G, Hjalmarson A and Hoebeke J (1995) Functional epitope analysis of the second extracellular loop of the human heart muscarinic acetylcholine receptor. J Mol Cell Cardiol 27, 427-436

26. Zhang S, He Z, Wang J et al (2015) Mitochondrial Ultrastructural Alterations and Declined M2 Receptor Density Were Involved in Cardiac Dysfunction in Rats after Long Term Treatment with Autoantibodies against M2 Muscarinic Receptor. PLoS One 10, e0129563

27. Yoshizawa A, Nagai S, Baba Y et al (2012) Autoimmunity against $M(2)$ muscarinic acetylcholine receptor induces myocarditis and leads to a dilated cardiomyopathy-like phenotype. Eur J Immunol 42, 1152-1163

28. Palmer JW, Tandler B and Hoppel CL (1977) Biochemical properties of subsarcolemmal and interfibrillar mitochondria isolated from rat cardiac muscle. J Biol Chem 252, 8731-8739

29. Shin $G$, Sugiyama $M$, Shoji $T$, Kagiyama $A$, Sato $H$ and Ogura R (1989) Detection of mitochondrial membrane damages in myocardial ischemia with ESR spin labeling technique. J Mol Cell Cardiol 21, 1029-1036

30. Palmer JW, Tandler B and Hoppel CL (1985) Biochemical differences between subsarcolemmal and interfibrillar mitochondria from rat cardiac muscle: effects of procedural manipulations. Arch Biochem Biophys 236, 691-702

31. Hoppel CL, Tandler B, Parland W, Turkaly JS and Albers LD (1982) Hamster cardiomyopathy. A defect in oxidative phosphorylation in the cardiac interfibrillar mitochondria. J Biol Chem 257, 1540-1548

32. D'Angelo DD, Sakata Y, Lorenz JN et al (1997) Transgenic Galphaq overexpression induces cardiac contractile failure in mice. Proc Natl Acad Sci U S A 94, 8121-8126
33. Sakata Y, Hoit BD, Liggett SB, Walsh RA and Dorn GW 2nd (1998) Decompensation of pressure-overload hypertrophy in G alpha q-overexpressing mice. Circulation 97, 1488-1495

34. Yussman MG, Toyokawa T, Odley A et al (2002) Mitochondrial death protein Nix is induced in cardiac hypertrophy and triggers apoptotic cardiomyopathy. Nat Med 8, 725-730

35. Syed F, Odley A, Hahn HS et al (2004) Physiological growth synergizes with pathological genes in experimental cardiomyopathy. Circ Res 95, 1200-1206

36. Diwan A, Wansapura J, Syed FM, Matkovich SJ, Lorenz JN and Dorn GW 2nd (2008) Nix-mediated apoptosis links myocardial fibrosis, cardiac remodeling, and hypertrophy decompensation. Circulation 117, 396-404

37. Dorn GW 2nd (2010) Mitochondrial pruning by Nix and BNip3: an essential function for cardiac-expressed death factors. J Cardiovasc Transl Res 3, 374-383

38. Archer SL (2013) Mitochondrial dynamics-mitochondrial fission and fusion in human diseases. N Engl J Med 369, 2236-2251

39. Song M, Mihara K, Chen Y, Scorrano L and Dorn GW 2nd (2015) Mitochondrial fission and fusion factors reciprocally orchestrate mitophagic culling in mouse hearts and cultured fibroblasts. Cell Metab 21, 273-285

40. Chen Y and Dorn GW 2nd (2013) PINK1-phosphorylated mitofusin 2 is a Parkin receptor for culling damaged mitochondria. Science 340, 471-475

41. Song M, Chen Y, Gong G, Murphy E, Rabinovitch PS and Dorn GW 2nd (2014) Super-suppression of mitochondrial reactive oxygen species signaling impairs compensatory autophagy in primary mitophagic cardiomyopathy. Circ Res 115, 348-353

42. Chen Y, Liu Y and Dorn GW 2nd (2011) Mitochondrial fusion is essential for organelle function and cardiac homeostasis. Circ Res 109, 1327-1331

43. Papanicolaou KN, Kikuchi R, Ngoh GA et al (2012) Mitofusins 1 and 2 are essential for postnatal metabolic remodeling in heart. Circ Res 111, 1012-1026

44. Chen L, Liu T, Tran A et al (2012) OPA1 mutation and late-onset cardiomyopathy: mitochondrial dysfunction and mtDNA instability. J Am Heart Assoc 1, e003012

45. Song $M$ and Dorn GW 2nd (2015) Mitoconfusion: noncanonical functioning of dynamism factors in static mitochondria of the heart. Cell Metab 21, 195-205

46. Kubli DA and Gustafsson AB (2012) Mitochondria and mitophagy: the yin and yang of cell death control. Circ Res 111, 1208-1221

47. Delbridge LM, Mellor KM, Taylor DJ and Gottlieb RA (2015) Myocardial autophagic energy stress responsesmacroautophagy, mitophagy, and glycophagy. Am J Physiol Heart Circ Physiol 308, H1194-1204

48. Shirihai OS, Song M and Dorn GW 2nd (2015) How Mitochondrial Dynamism Orchestrates Mitophagy. Circ Res 116, 1835-1849

49. Ashrafian $\mathrm{H}$, Docherty $\mathrm{L}$, Leo $\mathrm{V}$ et al (2010) A mutation in the mitochondrial fission gene Dnm1l leads to cardiomyopathy. PLoS Genet 6, e1001000

50. Gray MW, Burger G and Lang BF (1999) Mitochondrial evolution. Science 283, 1476-1481 
51. Fosslien E (2003) Review: Mitochondrial medicine--cardiomyopathy caused by defective oxidative phosphorylation. Ann Clin Lab Sci 33, 371-395

52. Wang J, Wilhelmsson H, Graff C et al (1999) Dilated cardiomyopathy and atrioventricular conduction blocks induced by heart-specific inactivation of mitochondrial DNA gene expression. Nat Genet 21, 133-137

53. Li H, Wang J, Wilhelmsson $\mathrm{H}$ et al (2000) Genetic modification of survival in tissue-specific knockout mice with mitochondrial cardiomyopathy. Proc Natl Acad Sci U S A 97, 3467-3472

54. Wisneski JA, Gertz EW, Neese RA and Mayr M (1987) Myocardial metabolism of free fatty acids. Studies with 14C-labeled substrates in humans. J Clin Invest 79, 359366

55. Stanley WC and Chandler MP (2002) Energy metabolism in the normal and failing heart: potential for therapeutic interventions. Heart Fail Rev 7, 115-130

56. Stanley WC, Lopaschuk GD, Hall JL and McCormack JG (1997) Regulation of myocardial carbohydrate metabolism under normal and ischaemic conditions. Potential for pharmacological interventions. Cardiovasc Res 33, 243-257

57. Graham BH, Waymire KG, Cottrell B, Trounce IA, MacGregor GR and Wallace DC (1997) A mouse model for mitochondrial myopathy and cardiomyopathy resulting from a deficiency in the heart/muscle isoform of the adenine nucleotide translocator. Nat Genet 16, 226-234

58. Engel AG (1999) Myofibrillar myopathy. Ann Neurol 46, 681-683

59. Paulin D, Huet A, Khanamyrian L and Xue Z (2004) Desminopathies in muscle disease. J Pathol 204, 418-427

60. Vicart P, Caron A, Guicheney P et al (1998) A missense mutation in the alphaB-crystallin chaperone gene causes a desmin-related myopathy. Nat Genet 20, 92-95

61. Wang X, Osinska H, Dorn GW 2nd et al (2001) Mouse model of desmin-related cardiomyopathy. Circulation 103, 2402-2407

62. Maloyan A, Sanbe A, Osinska H et al (2005) Mitochondrial dysfunction and apoptosis underlie the pathogenic process in alpha-B-crystallin desmin-related cardiomyopathy. Circulation 112, 3451-3461

63. Badorff C, Lee GH, Lamphear BJ et al (1999) Enteroviral protease 2A cleaves dystrophin: evidence of cytoskeletal disruption in an acquired cardiomyopathy. Nat Med 5, 320-326

64. Feng J, Yan J, Buzin $\mathrm{CH}$, Towbin JA and Sommer SS (2002) Mutations in the dystrophin gene are associated with sporadic dilated cardiomyopathy. Mol Genet Metab 77, $119-126$

65. Vatta M, Stetson SJ, Perez-Verdia A et al (2002) Molecular remodelling of dystrophin in patients with end-stage cardiomyopathies and reversal in patients on assistance-device therapy. Lancet 359, 936-941

66. Khairallah M, Khairallah R, Young ME, Dyck JR, Petrof BJ and Des Rosiers C (2007) Metabolic and signaling alterations in dystrophin-deficient hearts precede overt cardiomyopathy. J Mol Cell Cardiol 43, 119-129

67. Nakayama H, Chen X, Baines CP et al (2007) Ca2+- and mitochondrial-dependent cardiomyocyte necrosis as a primary mediator of heart failure. J Clin Invest 117, 2431-2444
68. Hajjar RJ, Liao R, Young JB, Fuleihan F, Glass MG and Gwathmey JK (1993) Pathophysiological and biochemical characterisation of an avian model of dilated cardiomyopathy: comparison to findings in human dilated cardiomyopathy. Cardiovasc Res 27, 2212-2221

69. Zhang M, Wei J, Shan H et al (2013) Calreticulin-STAT3 signaling pathway modulates mitochondrial function in a rat model of furazolidone-induced dilated cardiomyopathy. PLoS One 8, e66779

70. Armstrong PW, Stopps TP, Ford SE and de Bold AJ (1986) Rapid ventricular pacing in the dog: pathophysiologic studies of heart failure. Circulation 74, 1075-1084

71. Spinale FG, Hendrick DA, Crawford FA, Smith AC, Hamada Y and Carabello BA (1990) Chronic supraventricular tachycardia causes ventricular dysfunction and subendocardial injury in swine. Am J Physiol 259, H218229

72. Ide $\mathrm{T}$, Tsutsui $\mathrm{H}$, Kinugawa $\mathrm{S}$ et al (1999) Mitochondrial electron transport complex I is a potential source of oxygen free radicals in the failing myocardium. Circ Res 85, 357-363

73. Melov S, Coskun P, Patel M et al (1999) Mitochondrial disease in superoxide dismutase 2 mutant mice. Proc Natl Acad Sci U S A 96, 846-851

74. Lefrak EA, Pitha J, Rosenheim S and Gottlieb JA (1973) A clinicopathologic analysis of adriamycin cardiotoxicity. Cancer 32, 302-314

75. Gilladoga AC, Manuel C, Tan CT, Wollner N, Sternberg SS and Murphy ML (1976) The cardiotoxicity of adriamycin and daunomycin in children. Cancer 37, 1070-1078

76. Takemura G and Fujiwara $\mathrm{H}$ (2007) Doxorubicin-induced cardiomyopathy from the cardiotoxic mechanisms to management. Prog Cardiovasc Dis 49, 330-352

77. Sawyer DB (2013) Anthracyclines and heart failure. N Engl J Med 368, 1154-1156

78. van der Vijgh WJ, van Velzen D, van der Poort JS et al (1988) Morphometric study of myocardial changes during doxorubicin-induced cardiomyopathy in mice. Eur J Cancer Clin Oncol 24, 1603-1608

79. Shenasa H, Calderone A, Vermeulen M et al (1990) Chronic doxorubicin induced cardiomyopathy in rabbits: mechanical, intracellular action potential, and beta adrenergic characteristics of the failing myocardium. Cardiovasc Res 24, 591-604

80. Lebrecht D, Setzer B, Ketelsen UP, Haberstroh J and Walker UA (2003) Time-dependent and tissue-specific accumulation of mtDNA and respiratory chain defects in chronic doxorubicin cardiomyopathy. Circulation 108, 2423-2429

81. Kerr DS (2010) Treatment of mitochondrial electron transport chain disorders: a review of clinical trials over the past decade. Mol Genet Metab 99, 246-255

82. Gurlek A, Tutar E, Akcil E et al (2000) The effects of L-carnitine treatment on left ventricular function and erythrocyte superoxide dismutase activity in patients with ischemic cardiomyopathy. Eur J Heart Fail 2, 189-193

83. Singh RB, Niaz MA, Rastogi V and Rastogi SS (1998) Coenzyme $Q$ in cardiovascular disease. J Assoc Physicians India 46, 299-306

84. Buyse GM, Van der Mieren G, Erb M et al (2009) Long- 
term blinded placebo-controlled study of SNT-MC17/idebenone in the dystrophin deficient $\mathrm{mdx}$ mouse: cardiac protection and improved exercise performance. Eur Heart 30, 116-124

85. Lagedrost SJ, Sutton MS, Cohen MS et al (2011) Idebenone in Friedreich ataxia cardiomyopathy-results from a 6-month phase III study (IONIA). Am Heart J 161, 639-645 e631

86. Rizos I (2000) Three-year survival of patients with heart failure caused by dilated cardiomyopathy and L-carnitine administration. Am Heart J 139, S120-123

87. Abozguia K, Elliott P, McKenna W et al (2010) Metabolic modulator perhexiline corrects energy deficiency and improves exercise capacity in symptomatic hypertrophic cardiomyopathy. Circulation 122, 1562-1569

88. Lionetti V, Linke A, Chandler MP et al (2005) Carnitine palmitoyl transferase-I inhibition prevents ventricular remodeling and delays decompensation in pacing-induced heart failure. Cardiovasc Res 66, 454-461

89. Bersin RM, Wolfe C, Kwasman M et al (1994) Improved hemodynamic function and mechanical efficiency in congestive heart failure with sodium dichloroacetate. J Am Coll Cardiol 23, 1617-1624

90. Lewis JF, DaCosta M, Wargowich $T$ and Stacpoole $P$ (1998) Effects of dichloroacetate in patients with congestive heart failure. Clin Cardiol 21, 888-892

91. Arakawa K, Kudo T, Ikawa M et al (2010) Abnormal myocardial energy-production state in mitochondrial cardiomyopathy and acute response to L-arginine infusion.
C-11 acetate kinetics revealed by positron emission tomography. Circ J 74, 2702-2711

92. Lebrecht D, Geist A, Ketelsen UP, Haberstroh J, Setzer B and Walker UA (2007) Dexrazoxane prevents doxorubicin-induced long-term cardiotoxicity and protects myocardial mitochondria from genetic and functional lesions in rats. Br J Pharmacol 151, 771-778

93. Konorev EA, Kennedy MC and Kalyanaraman B (1999) Cell-permeable superoxide dismutase and glutathione peroxidase mimetics afford superior protection against doxorubicin-induced cardiotoxicity: the role of reactive oxygen and nitrogen intermediates. Arch Biochem Biophys 368, 421-428

94. Fisher PW, Salloum F, Das A, Hyder H and Kukreja RC (2005) Phosphodiesterase-5 inhibition with sildenafil attenuates cardiomyocyte apoptosis and left ventricular dysfunction in a chronic model of doxorubicin cardiotoxicity. Circulation 111, 1601-1610

95. Wagner JA, Weisman HF, Snowman AM, Reynolds IJ, Weisfeldt ML and Snyder SH (1989) Alterations in calcium antagonist receptors and sodium-calcium exchange in cardiomyopathic hamster tissues. Circ Res 65, 205-214

96. Li Y, Huang TT, Carlson EJ et al (1995) Dilated cardiomyopathy and neonatal lethality in mutant mice lacking manganese superoxide dismutase. Nat Genet 11, 376-381

97. Shipp JC, Opie LH and Challoner D (1961) Fatty acid and glucose metabolism in the perfused heart. Nature 189, 1018-1019 